\title{
PENERAPAN MODEL PEMBELAJARAN NOVICK UNTUK MENINGKATKAN HASIL BELAJAR FISIKA SISWA KELAS $X$ SMA NEGERI 1 SOJOL
}

\author{
Ardiansyah, Muhammad. Ali, Yusuf Kendek \\ Ardhye.physics@yahoo.com \\ Program Studi Pendidikan Fisika FKIP Universitas Tadulako \\ Jl. Soekarno Hatta Km. 9 Kampus Bumi Tadulako Tondo Palu - Sulawesi Tengah
}

\begin{abstract}
Abstrak - Penelitian ini bertujuan untuk meningkatkan hasil belajar fisika melalui penerapan Model pembelajaran Novick pada siswa kelas X SMA Negeri 1 Sojol. Penelitian ini menggunakan Desain "The non rendomized control group pretest-posttest design". Pengambilan sampel dilakukan secara purposive sampling. Sampel dalam penelitian ini yaitu kelas X MIA A sebagai kelas eksperimen dan kelas X MIA B sebagai kelas kontrol. Instrumen yang digunakan dalam penelitian ini meliputi tes hasil belajar. Analisis data tes dilakukan dengan teknik statistik uji-t dua pihak. Berdasarkan hasil pengolahan data penelitian, diperoleh nilai $t_{\text {hitung }}$ dengan taraf nyata $\mathrm{a}=0,05$ yaitu $-\mathrm{t}_{(1-0,5 \mathrm{a})}<\mathrm{t}<\mathrm{t}_{(1-0,5 \mathrm{a})},(-1,67<0,10<1,67)$, dengan demikian $\mathrm{H}_{1}$ diterima dan $\mathrm{H}_{0}$ ditolak. artinya, terdapat perbedaan hasil belajar fisika siswa yang diberi pengajaran model pembelajaran novickdengan siswa yang diberi pengajaran konvensional. Hasil analisa menunjukkan bahwa penerapan model pembelajaran Novick dapat meningkatkan hasil belajar fisika pada siswa kelas X SMA Negeri 1 Sojol.
\end{abstract}

Kata Kunci: Model Pembelajaran Novick, Hasil Belajar

\section{PENDAHULUAN}

Pendidikan tidak akan terlepas dari kegiatan sehari-hari oleh manusia. Karena pendidikan dapat mengembangkan potensi seseorang serta dapat membentuk kepribadian, watak, karakter serta dengan pendidikan dapat mencerdaskan keidupan bangsa yang bermartabat dan berakhalak. Hal ini sesuai dengan UU No. 2 tentang sistem pendidikan Nasional pasal 3 menyatakan pendidikan Naional berfungsi mengembangkan kemampuan dan membentuk watak serta peradaban bangsa yang bermagfaat dalam rangka mencerdaskan kehidupan bangsa, bertujuan untuk mengembangkannya potensi peserta didik agar menjadi manusia yang beriman, berakhlak mulia, serta sehat berilmu, cakap, kreatif, mandiri dan menjadi warga yang berdemokrasi dan bertanggung jawab [1].

Fisika adalah salah satu mata pelajaran yang dapat mencerdaskan kehidupan bangsa hal ini disebabkan karena fisika merupakan salah satu ilmu universal yang menjadi landasan perkembangan teknologi modern yang bisa menjadi tolak ukur perkembangan serta kemajuan suatu negara. Oleh karena itu diperlukan suatu proses pengajaran yang baik untuk mata pelajaran fisika pada. Salah satu menggunakan model pembelajaran yang membuat siswa aktif adalah model pembelajaran Novick.

Model pembelajaran Novick merupakan model pembelajaran yang merujuk pada pandangan konstruktivisme. Gagasan utama dari model pembelajaran ini adalah proses perubahan konseptual dari pengetahuan awal siswa pada proses pembelajaran.

Model pembelajaran Novick adalah suatu model pembelajaran yang berawal dari konsep belajar, sebagai perubahan konseptual yang dikembangkan dari pendekatan konstruktivisme [2] mengemukakan, "Model pembelajaran Novick terdiri dari 3 fase, yaitu: fase pertama, mempertunjukkan kerangka kerja alternative siswa (exposing alternative frameworks) pada fase ini siswa diharapkan mengungkapkan konsepsi awal siswa agar guru mengenali pemahaman gagasan atau konsepsi awal siswa. Fase kedua, menciptakan konflik konseptual (creating conceptual conflict), pada fase konflik kognitif memicu siswa untuk lebih tertantang untuk belajar, pada fase ini siswa lebih tertantang dalam struktur kognitif siswa yang dia ketahui sebelumnya dan fakta apa yang siswa lihat pada kehidupan sehari hari belum cocok dengan skema yang telah ada. Fase ketiga mendorong terjadinya akomodasi kognitif (encouraging cognitive accomodation). Pada fase ini akomodasi kognitif bertujuan untuk membentuk skema baru yang cocok 
dengan ransangan yang baru atau modifikasi skema yang ada sehingga sesuai dengan konsep yang ilmiah.

Siswa pada dasarnya sebelum memasuki ruang belajar (kelas), siswa sudah mempunyai prakonsep ataupun pengetahuan awal yang di diperoleh dari lingkungan sekitar, buku-buku serta dari pengalaman hidupnya. Tidak sedikit pengetahuan dan prakonsep yang dikonstruksi oleh siswa tidak sesuai dengan konsep ilmiah. Sehingga penting perlunya perubahan konseptual dari pengetahuan awal (prakonsep) kearah yang benar. "Perubahan konseptual terjadi melalui akomodasi kognitif yang berawal dari pengetahuan awal siswa" [3] . Untuk menciptakan proses akomodasi kognitif

Terjadinya akomodasi yaitu mula-mula anak itu harus merasa tidak puas dengan gagasan yang ada (konsepsi lama siswa) [4] . Walaupun demikian, ketidakpuasan tidak cukup untuk mengganti gagasan lama dengan gagasan baru, harus ditambah dengan tiga kondisi yaitu: 1). Gagasan baru harus bersifat intelligible (mudah dimengerti), 2).gagasan baru harus bersifat Plausible (masuk akal), dan 3) gagasan baru harus bersifat fruitful (memberi suatu kegunaan).

\section{METODOLOGI PENELITIAN}

Mengacu pada tujuan penelitian yang ingin dicapai, jenis penelitian ini adalah kuasi eksperimen, Desain penelitian menggunakan Non rendomized control group pretest-postest design.

Subjek penelitian adalah seluruh siswa kelas $X$ SMA Neg.1 Sojol yang terdaftar pada tahun pelajaran 2014/2015. Sampel penelitian adalah sebagian yang diambil dari populasi dengan menggunakan cara-cara tertentu. Cara penarikan sampel dalam penelitian ini dengan tehnik purposive sampling atau penentuan sampel dengan pertimbangan tertentu dan secara sengaja. Hal yang menjadi pertimbangan adalah nilai rata-rata dan usulan dari guru mata pelajaran fisika disekolah tersebut. Variabel bebas adalah model pembelajaran Novick dan model pembelajaran konvensionan dan variabel terikatnya adalah hasil belajar.

Instrumen yang digunakan dalam penelitian ini adalah tes hasil belajar (THB) fisika materi GLB dan GLBB. Tes tersebut digunakan untuk mengetahui hasil belajar siswa dalam belajar fisika pada kelas yang menjadi sampel penelitian. Tes dibuat dalam pilihan ganda sebanyak 30 item soal. Setelah data dari hasil uji coba terkumpul, kemudian dilakukan penganalisaan data untuk mengetahui nilai validitas, reliabilitas, daya pembeda dan indeks kesukaran.

Pengujian hipotesis ini dilakukan dengan menggunakan uji-t (uji dua pihak) dengan pasangan hipotesis sebagai berikut :

$$
\begin{aligned}
\mathrm{Ho}: \mu \mathrm{O}=\mu_{1} ; & \text { tidak ada perbedaan hasil } \\
& \text { belajar fisika menggunakan } \\
& \text { model pembelajaran Novick } \\
& \text { dengan model pembelajaran } \\
& \text { Konvensional } \\
\mathrm{H}_{1}: \mu \mathrm{O} \neq \mu ; & \text { ada perbedaan hasil belajar } \\
& \text { fisika menggunakan model } \\
& \text { pembelajaran Novick dengan } \\
& \text { model pembelajaran } \\
& \text { Konvensional }
\end{aligned}
$$

Rumus yang digunakan untuk uji kesamaan dua rata-rata [5] :

$$
\begin{gathered}
t_{\text {hitung }}=\frac{\mathrm{x}_{\mathrm{A}}-\mathrm{x}_{\mathrm{B}}}{\mathrm{s} \sqrt{\frac{1}{\mathrm{n}_{\mathrm{A}}+\frac{1}{\mathrm{n}_{\mathrm{B}}}}}} \\
\text { dimana : } \quad \mathrm{S}=\frac{\sqrt{\left(\mathrm{n}_{\mathrm{A}}-1\right) \mathrm{S}_{\mathrm{A}}^{2}+\left(\mathrm{n}_{\mathrm{A}}-1\right) S_{B}^{2}}}{\mathrm{n}_{\mathrm{A}}+\mathrm{n}_{\mathrm{B}}-2}
\end{gathered}
$$

dengan :

$\mathrm{X}_{\mathrm{A}}$ : Skor rata-rata kelas eksperim en

$X_{B}$ : Skor rata-rata kelas Kontrol

$\mathrm{n}_{\mathrm{A}} \quad$ : Jumlah siswa kelas eksperimen

$\mathrm{n}_{\mathrm{B}} \quad$ : Jumlah siswa kelas kontrol

$\mathrm{S} \quad$ : Simpangan baku gabungan

Dengan kriteria pengujian yakni terima $\mathrm{H}_{\mathrm{o}}$ jika-t $(1.05 \alpha)$ pada taraf nyata $\alpha=0,05$ dan $\mathrm{dk}=\mathrm{n}_{1}$ $+\mathrm{n}_{2}-2$ serta untuk nilai t lainnya Ho ditolak.

\section{HASIL DAN PEMBAHASAN}

\section{HASIL PENELITIAN}

Pada hasil penelitian ini meliputi hasil selama kegiatan pembelajaran Novick. Hasil penelitian yang melibatkan dua kelas, yakni kelas eksperimen dan kelas kontrol pada kelas X MIA A dan B SMAN 1 Sojol. Berikut data hasil penelitian yang telah diperoleh.

TABEL 1. HASIL UJI NORMALITAS PRETEST KELOMPOK EKSPERIMEN DAN KELOMPOK CONTROL.

\begin{tabular}{|l|l|l|}
\hline \multirow{2}{*}{ Uraian } & \multicolumn{2}{|l|}{ Kelompok } \\
\cline { 2 - 3 } & Eksperimen & Kontrol \\
\hline$X^{2}$ tabel \\
$\begin{array}{l}(\mathrm{dk}=3, \alpha=0,05) \\
X^{2} \text { hitung }\end{array}$ & 7,81 & 7,81 \\
\hline
\end{tabular}

Berdasarkan kriteria $X^{2}$ hitung dan harga $X^{2}$ tabel untuk kelompok eksperimen dan 
kelompok kontrol ternyata diperoleh $X^{2}$ hitung $<$ $X^{2}$ tabel. Hal ini menunjukkan bahwa kelompok kontrol dan kelompok eksperimen berdistribusi normal.

TABEL 2 HASIL PENGUJIAN HOMOGENITAS KELOMPOK EKSPERIMEN DAN KELOMPOK KONTROL

\begin{tabular}{|c|c|c|c|c|}
\hline No & Tes & Kelompok & $\begin{array}{l}\text { Nilai } \\
\text { varian }\end{array}$ & Nilai $F$ \\
\hline \multirow[t]{2}{*}{1} & \multirow{2}{*}{ Pretest } & $\begin{array}{l}\text { Eksperime } \\
n\end{array}$ & 8,44 & $\begin{array}{l}F_{\text {hitung }}=0,9 \\
9\end{array}$ \\
\hline & & Kontrol & 8,49 & $\mathrm{~F}_{\text {tabel }}=1,68$ \\
\hline \multirow[t]{2}{*}{2} & \multirow{2}{*}{$\begin{array}{l}\text { Posttes } \\
t\end{array}$} & $\begin{array}{l}\text { Eksperime } \\
n\end{array}$ & 7,31 & $\begin{array}{l}F_{\text {hitung }}=1,1 \\
3\end{array}$ \\
\hline & & Kontrol & 6,45 & $F_{\text {tabel }}=1,68$ \\
\hline
\end{tabular}

Berdasarkan kriteria $F_{\text {hitung }}$ dan harga $F_{\text {tabel }}$ dengan taraf nyata $a=0,05$ untuk kelompok eksperimen dan kelompok kontrol ternyata diperoleh $\mathrm{F}_{\text {hitung }}<\mathrm{F}_{\text {tabel. }}$. Hal ini menunjukkan bahwa kedua kelompok yang dijadikan sampel berasal dari populasi yang homogen. Uji beda rata-rata skor hasil belajar (posttest) kelompok eksperimen dan kelompok kontrol. Uji ini digunakan untuk megetahui keadaan hasil belajar kelompok eksperimen dan kelompok kontrol. Berdasarkan hasil perhitungan diperoleh nilai $t_{\text {hitung }} 2,67$. Sedangkan nilai $\mathrm{t}_{\text {tabel }}$ dengan $-\mathrm{t}_{(1-0,5 \mathrm{a})}<\mathrm{t}<\mathrm{t}_{(1-}$ $0,5 a)$, pada taraf nyata $\mathrm{a}=0,05$ dan $\mathrm{dk}=\left(\mathrm{n}_{1}+\right.$ $\left.n_{2}-2\right)=42+43-2=83$, diperoleh $t_{0,95(83)}=$ 1,67 . Hal ini berarti, nilai $t_{\text {hitung }}$ berada pada daerah penolakan $\mathrm{H}_{0}$ dan $\mathrm{H}_{1}$ diterima. Dengan demikian dapat disimpulkan bahwa penerapan model pembelajaran Novick dapat meningkatkan hasil belajar Fisika siswa kelas $X$ SMAN 1 Sojol

Dari hasil pengujian hipotesis, model pembelajaran Novick dapat meningkatkan hasil belajar fisika siswa kelas X SMA Negeri 1 Sojol, hal ini karena model pembelajaran Novick menggunakan strategi konflik kogmitif yang melatih siswa mengkonstruksi pengetahuannya sendiri berdasarkan pengetahuan awal yang dia miliki sehingga dapat mengetahui konsep materi secara tepat.

Pembelajaran dikelas eksperimen dimulai dengan guru yang berusaha menggali pemahaman awal siswa mengenai materi yang akan diajarkan. Guru memberikan pertanyaanpertanyaan awal yang dapat menuntun siswa untuk memberikan ide atau pemahaman awalnya. Selanjutnya siswa dituntun untuk membuktikan pemahaman awal mereka dengan melakukan eksperimen sederhana yang mereka lakukan dalam kelompok mereka. Tiap kelompok beranggotakan 7-8 orang. Setiap kelompok mendapat LKK yang berisi pertanyaan-pertanyaan yang akhirnya mereka harus memberikan kesimpulan. Di akhir kegiatan salah satu kelompok diminta untuk mempresentasikan hasil eksperimen mereka dan kelompok lain memperhatikan dan menanggapi dan memberi pertanyaan jika ada yang kurang dipahami. Pada tahap ini guru memberikan pengarahan tentang hasil diskusi mereka. Dan pada tahap akhir siswa dan guru sma-sama menarik kesimpulan dan di akhiri dengan pemberian tugas rumah untuk siswa.

Pada kelas kontrol pembelajaran yang dilakukan tidak jauh berbeda dengan pembelajaran seperti biasa. Di kelas ini digunakan pembelajaran konvensional dimana peran guru sangat dominan dan siswa cenderung bersifat pasif. Megapa dikatakan bersifat pasif ? Karena siswa hanya diminta untuk memperhatikan penjelasan yang diberikan oleh guru kemudian diberi tugas dan diakhiri dengan pemberian tugas rumah. Model pembelajaran ini cenderung membuat siswa bosan karena mereka kurang aktif. Sedangkan jika dilihat dari latar belakang mereka yang masih bersifat anak-anak yang masih memiliki rasa ingin bermain.

Peningkatan hasil belajar pada kelas eksperimen ini juga terjadi karena adanya perbedaan perlakuan yang dilakukan terhadap kedua kelas. Karena pada kelas eksperimen diberikan pembelajaran novick sedangkan pada kelas kontrol diberikan pembelajaran konvensional. Dengan demikian, siswa pada kelas eksperimen tingkat pemahamannya lebih tinggi dibanding kelas kontrol karena siswa dituntut untuk mencari dan menemukan sendiri konsep yang diajarkan. Karena, dengan siswa yang aktif dan menemukan sendiri apa yang mereka pelajari dan menggabungkan dengan pemahaman mereka, maka siswa cenderung mengingat dan memahami tentang konsep yang diberikan. Dengan cara pembelajaran seperti ini maka siswa menjadi pusat pembelajaran sedangkan guru hanya sebagai fasilitator. Pada penelitian najmawati[5] disebutkan bahwa model pembelajaran novick dapat membuat siswa lebih aktif dan motivasi belajar siswa mencapai $86 \%$, pada penelian saya lakukan juga siswa yang mendapatkan pengajaran model pembelajaran Novick membuat siswa lebihh akatif dan motivasi belajarnya menjadi bertambah. 


\section{KESIMPULAN}

Berdasarkan hasil pengolahan dan analisa data penelitian, maka dapat disimpulkan bahwa terdapat perbedaan hasil belajar fisika dengan menggunakan Model Pembelajaran Novick dengan model pembelajaran konvensional pada siswa kelas $X$ SMAN 1 Sojol. Hal ini dapat diketahui melalui hasil pengujian pengujian hipotesis dengan menggunkan uji-t pada tes akhir memberikan hasil nilai thitung 2,67. Sedangkan nilai tabel dengan $-\mathrm{t}_{(1-0,5 \mathrm{a})}<\mathrm{t}<\mathrm{t}_{(1-0,5 \mathrm{a})}$, pada taraf nyata $a=0,05$

\section{DAFTAR PUSTAKA}

[1] Oemar Hamalik. 2007. Dasar-Dasar Pengembangan Kurikulum. PT. Remaja Rosdakarya: Bandung

[2] Novick, Shimshon., \& Nussbaum, Joseph. 1982. Alternative Frameworks, Conceptual Conflict and Accommodation: toward a Principled Teaching Strategy. Jurnal Intructional Science, 11, issu 3, 183-200. Elsevier Scientific Publlishing Company, Amsterdam. (online). http://link.springer.com/article/10.107/BF00414279.

[3] Marliany, E. 2007. Pengaruh Model Pembelajaran Novick Terhadap Kemampuan Komunikasi Matematika Siswa SMP. Skripsi Pendidikan Matematika UNPAC:Bandung.

[4] Dahar, Ratna Willis.2011.Teori-Teori Belajar dan Pembelajaran. PT. Glora Angkasa Pratama: Bandung

[5] Sudjana, S. 2005. Metoda Statistika Edisi 6. Bandung : Tarsito.

[6] Sulaiman, N. 2012. Efektivitas Model Pembelajaran Novick dalam Pembelajaran Kimia Kelas XII IA $\mathrm{I}_{2}$ SMAN 1 Donri-Donri(Studi pada Materi Pokok Gugus fungsi). Jurnal Chemica Vol. 13: 67-73 